\title{
FONDASI ETIS EKONOMI PADA MASA RASULULLAH (SEBUAH KAJIAN HISTORIS-NORMATIF)
}

\author{
Ayief Fathurrahman \\ Universitas Muhammadiyah Yogyakarta \\ e-mail: ayief_ospp@yahoo.com
}

\begin{abstract}
It is certainly undeniable that in Islam the source of ethics in the line of life is the Prophet Muhammad, including ethics of economic activity. Islam which was the beginning of its glory in the time of the Prophet Muhammad also had the concept of an economic system that should be used as a lesson and reference materials. Therefore, this paper will explain the economic activities of the preIslamic Arabs as a comparison with the economic activities that have been straightened out by the Messenger of Allah, which includes an initial strategy to build the economy of Medina, fiscal policy, so as to achieve social equity. The result of research shows that the economic activity of the pre-Islamic Arabs had become the World Trade Center, both in the southern part of the Arabian Peninsula which was managed by the Saba kingdom and the Himyar government with the dominant agricultural sector having fertile land. It is also supported by the presence of the Maarib giant dam. In the northern part of the Arab, Hijaz (Makkah) which was influenced by outsiders such as Persia and Rome, with the most prominent trade sector, because the territory was barren and arid, but the geographical location was strategic as a place for the caravans to stop. The economic characteristics of the Prophet's time were social-religious which emphasized cooperative work participation applied to Muhajirin and Ansar which led to increased income distribution and welfare. This is where the concept of economic democracy of the Prophet is seen which does not have to be interpreted as the enactment of the principle of equal treatment, because according to the Prophet the Have Not needs to get a partial treatment. In principle, the Messenger of Allah highly prioritizes the achievement of mutual welfare.
\end{abstract}

\section{Keywords: Economic Ethical Foundation, Historical-Normative Study, Rasulullah Era}

\section{Pendahuluan}

Dewasa ini, telah muncul gagasan tentang berlakunya perfect liberty dalam wujud semangat individu untuk bersaing dan membentuk mekanisme free competition dalam kehidupan berekonomi. Asumsi dasar ini, berangkat dari kapitalisme Smithian, yaitu bahwa (1) kebutuhan manusia yang tidak terbatas, (2) sumber-sumber ekonomi yang relatif terbatas, (3) pengejaran pemenuhan maksimal kebutuhan individual (utility maximizatioan of self interest) yang relatif tidak terbatas. ${ }^{1}$

Di samping itu, terbangunnya asumsi dasar bahwa manusia rasional adalah manusia yang berdasar inisiatif individunya yang mengejar utilitas ekonomi optimal, yaitu mencapai maximun gain dan minimum sacrifice, ia bersaing dalam mekanisme pasar, berpedoman pada laissez faire laissez-passer yang meneguhkan doktrin non-interference berdasar individual

\footnotetext{
${ }^{1}$ Sri Edi Swasono, Ekspose Ekonomika Globalisme dan Kompetensi Sarjana Ekonomi (Yogyakarta: Pusat Studi Ekonomi Pancasila (Pustep)-UGM, 2003), 2-3.
} 
freedom of action. Manusia rasional semacam ini dikenal dengan homo economicus (yang berseberangan dengan homo ethicus). ${ }^{2}$

Namun, asumsi dasar di atas yang termuat dalam sistem kapitalisme akhir-akhir ini sudah mulai mengalami kehilangan kepercayaan masyarakat dan menunjukkan tanda-tanda kebinasaan. Betapa tidak, semenjak sistem kapitalisme mendominasi sistem perekonomian dunia, hampir semua Negara pernah mengalami krisis moneter yang menggoyahkan stabilitas Negara. Dalam sejarah ekonomi, krisis demi krisis ekonomi terus berulang tiada henti, sejak tahun 1923,1930, 1940, 1970, 1980, 1990, dan 1998-2001, bahkan pada tahun 2008 krisis semakin mengkhawatirkan dengan munculnya krisis finansial di Amerika Serikat yang memberikan efek domino ke berbagai negara di penjuru dunia. ${ }^{3}$ Di dalam bukunya The History of Money from Ancient time to Present Day (1996), Roy Davies dan Glyn Davies menjelaskan dengan jelas kronologi krisis ekonomi dunia secara menyeluruh. Sepanjang Abad 20 telah terjadi lebih 20 kali krisis besar yang melanda banyak negara. Ini berarti, ratarata setiap 5 tahun terjadi krisis keuangan hebat yang mengakibatkan penderitaan bagi ratusan juta umat manusia. ${ }^{4}$

Atas kenyataan inilah, belakangan muncul ide dari banyak kalangan untuk mengembalikan ilmu ekonomi pada sifat humanisnya, sebagaimana ketika dulu ia dimunculkan oleh pemikir-pemikir sosiologi besar seperti Adam Smith dan Max Weber. Hans Kung misalnya, melalui bukunya yang bertitel A Global Ethics for Global Politics and Economics ${ }^{5}$ mencoba menawarkan apa yang ia sebut dengan "etika global" (global ethics), sebagai pemecah kebuntuan yang dihadapi ilmu politik dan ekonomi modern.

Di Indonesia, sebenarnya sudah sejak lama gugatan moral terhadap ilmu ekonomi neoklasikal ini. Adalah Muhammad Hatta sang proklamator bangsa yang mempersiapkan sistem ekonomi Indonesia, yang kemudian dikenal dengan Pasal 33 UUD 1945, yang bertumpu pada paham kesejahteraan sosial. Kesejahteraan sosial hanya bisa terwujud jika negara hadir di dalamnya. Karena negara memegang otoritas secara konstitusional untuk mewujudkan kesejahteraan sosial, kemadirian dan yang paling penting adalah menegakkan keadilan di dalam ekonomi, mengahapus ketimpangan dan kesenjangan yang terjadi di tengah masyarakat.

Di dalam catatan sejarah perekonomian Islam, tercatat banyak ekonom muslim yang memberikan kontribusi terhadap kelangsungan dan perkembangan pemikiran ekonomi pada khususnya dan peradaban dunia pada umumnya. ${ }^{6}$ Pemikiran ekonom muslim bertumpu pada sebuah konsep yang disebut sebagai "fungsi kesejahteraan sosial". Tema yang menjadi pangkal tolaknya adalah konsep maslahat atau kesejahteraan sosial atau utilitas (kebaikan

\footnotetext{
${ }^{2}$ Ibid., 4.

${ }^{3}$ Situasi ini dipicu oleh terjadinya kredit macet di sektor properti (subprime mortgage). Sehingga menyebabkan industri sub-prime mortgage skala besar seperti American Home Mortgage Investment Corporation (AHMI), Mortgage Guaranty Insurance Corporation (MGIC), dan New Century Financial Corporation (NCFC), jatuh bangkrut. Para investor kehilangan billiunan dollar untuk mencegah agar aset-aset sub-prime mortgage tidak lenyap. Tindakan ini kemudian memicu terjadinya huru-hara di pasar finansial global. Dikutip dari http://coenpontoh.wordpress.com/2007/09/19/efek-domino-krisis-properti-di-as/.

${ }^{4}$ Roy Davies and Glyn Davies, The History of Money From Ancient Time of Present Day (New York: Oxport University Press, 1996), 13.

${ }^{5}$ Judul terjemahan ke dalam Bahasa Inggris oleh John Bowden, 1997, dari versi aslinya yang berbahasa Jerman.

${ }^{6}$ Adiwarman Azwar Karim, Sejarah Pemikiran Ekonomi Islam (Jakarta: PT Raja Grafindo Persada, 2006$), 8$.
} 
bersama), yakni sebuah konsep yang mencakup semua aktivitas manusia dan membuat kaitan yang erat antara individu dan masyarakat. Hal ini sangat bertentangan dengan manusia rasional ala kapitalisme yang dikenal dengan homo economicus.

Dalam perspektif sejarah yang lebih luas, sejak manusia ada di muka bumi, maka sejak itu pula munculnya aktivitas ekonomi di dalam kehidupan manusia. Pada awal sejarahnya, aktivitas manusia hanya tertuju pada bagaimana caranya kebutuhan primer dapat dipenuhi dalam rangka mempertahankan hidup. Dengan kata lain, aktivitas ekonomilah yang pertama kali ada di dalam kehidupan manusia. Namun seiring dengan berjalanya waktu, aktivitas manusia berkembang sejalan dengan tuntutan zaman dengan segala ragamnya.

Dengan dasar sejarah di atas, maka Khan seorang pakar ekonomi dari Pakistan sebagaimana dikutip oleh Kholis, mengatakan bahwa ilmu ekonomi bertujuan mempelajari kesejahteraan manusia (falăh) yang dicapai dengan mengorganisir sumber-sumber daya bumi atas dasar kerjasama dan partisipasi. ${ }^{7}$ Oleh sebab itu, aktivitas ekonomi merupakan bagian dari kehidupan manusia. Setiap perilaku manusia didorong dari keinginannya untuk memenuhi kebutuhan hidupnya.

Oleh karena itu, ketika berbicara ekonomi, maka sama halnya kita berbicara hal yang klasik substanstif. Namun karena adanya perkembangan, maka di setiap masa dan zaman memiliki karakteristik yang berbeda sesuai dengan kebutuhan manusia. Namun harus sesuai dengan prinsip humanis yang sejatinya adalah sebagai fondasi etis bagi aktivitas ekonomi umat manusia di muka bumi ini.

Di dalam Islam, tentu tidak terbantahkan bahwa sumber etika di lini kehidupan adalah Rasulullah SAW, termasuk di dalamnya aktivitas ekonomi. Islam yang awal kejayaannya di masa Rasulullah SAW juga memiliki konsep sistem ekonomi yang patut dijadikan bahan pelajaran dan acuan. Oleh karena itu, pada tulisan ini akan dijelaskan aktivitas ekonomi bangsa Arab pra-Islam sebagai komparasi dengan aktivitas ekonomi yang telah diluruskan oleh Rasulullah, yang meliputi strategi awal membangun perkonomian Madinah, kebijakan fiskal, sehingga berhasil mewujudkan pemerataan sosial.

\section{Kondisi Perekonomian Bangsa Arab Pra-Islam}

Leboun dalam bukunya Haḍarāt al-Arab berkesimpulan bahwa tidak mungkin bangsa Arab tidak pernah memiliki peradaban yang tinggi, apalagi hubungan dagang multilateral berlangsung 2000 tahun lamanya. ${ }^{8}$ Bangsa Arab bukanlah bangsa bodoh yang senada dengan gelar "Jahiliyah" yang mereka sandang. Tapi dibalik gelar itu, justru mereka telah menyimpan peradaban dan menyisakan berbagai aspek kemajuan politik, ekonomi dan seni budaya. ${ }^{9}$ Gelar Jahiliyah hanyalah sebatas kesalahpahaman akidah mereka, sehingga merambat pada perilaku nista yang merajalela di dalam aspek kehidupan dan pola pikir mereka. ${ }^{10}$

Namun demikian harus diakui, bangsa Arab adalah bangsa yang mempunyai tampuk peradaban dan kemajuan. Bendungan raksasa Maarib warisan dari kerajaan Saba' dan

\footnotetext{
${ }^{7}$ Nur Kholis, "Penegakan Syariat Islam di Indonesia: Perspektif Ekonomi”, Jurnal Ilmiah Al Mawarid FIAI UII, edisi XVI Tahun 2006, 4. Baca juga, Muhammad Akram Khan, An Intrduction to Islamic Economics (Islamabad: IIIT Pakistan, 1989), 33.

${ }^{8}$ Gustav Leboun, Haḍarāt al-Arab (Kairo: Maṭba'ah İsā al-Bābi al-Halabi, t.t), 72.

${ }^{9}$ M. Abdul Karim. Sejarah Kebudayaan Islam (Yogyakarta: Pustaka Book Publisher, 2007), 49-50.

${ }^{10}$ Ibid.
} 
kerajaan Himyar di Yaman, bagian selatan jazirah Arab adalah bukti nyata di mana sangat memberikan pengaruh yang sangat besar, selain sebagai sumber air untuk wilayah kerajaan juga memberikan kesejahteraan bagi masyarakat, ${ }^{11}$ terutama pada sektor pertanian. Pertanian salah satu pondasi penting perekonomian bangsa Arab kala itu. Sejak 200 tahun sebelum kenabian Muhammad, mereka mengenal peralatan pertanian semi modern seperti alat bajak, cangkul, garu, dan tongkat kayu untuk menanam. ${ }^{12}$ Abdul Karim dalam bukunya Sejarah Pemikiran dan Peradaban Islam, mengklasifikasi sistem pertanian bangsa Arab ke dalam tiga sistem, antara lain sistem ijärah (sewa-menyewa), sistem bagi hasil produk (muzära'ah) ${ }^{13}$ dan sistem pendego (muḍāabah). ${ }^{14}$

Di samping itu, perdagangan merupakan bagian yang tak terpisahkan dari aktivitas perekonomian bangsa Arab pra-Islam. Pada masa pemerintahan Saba', bangsa Arab menjadi penghubung perdagangan antara Eropa dan dunia Timur. Setelah itu dilanjutkan dengan pemerintahan Himyar yang terkenal dengan kekuatan armada niaga yang menjelajahi Asia Selatan (India), China, Somalia dan Sumatera (Nusantara). ${ }^{15}$ Kemajuan perdagangan lintas negara kala itu pada awalnya dimungkinkan oleh sektor pertanian yang telah maju. Kemajuan tersebut ditandai dengan meningkatnya pertumbuhan ekonomi makro sektor ekspor-impor. ${ }^{16}$

Setelah kerajaan Himyar jatuh, jalur-jalur perdagangan didominasi oleh kerajaan Persia dan Romawi. Pusat perdagangan bangsa Arab serentak kemudian beralih ke Makkah. ${ }^{17}$ Karena letaknya geografisnya yang amat strategis, Makkah menjadi tempat persinggahan para kafilah dagang yang datang dan pergi menuju ke kota pusat perniagaan. Di Makkah telah tersedia pasar-pasar sebagai tempat pertukaran barang-barang antar para saudagar dari Asia Tengah, Syam, Yaman, Mesir, India, Irak, Etiopia, Persia dan Romawi. ${ }^{18}$

Mengingat posisi Makkah berada di suatu lembah yang tandus, maka yang menjadi sumber perekonomiannya adalah perdagangan. Seiring dengan berjalannya waktu, perdagangan menjadi faktor penentu utama hubungan sosial penduduk kota Makkah. Makkah disebut sebagai Ummul Qurā, yaitu sebuah pusat perniagaan besar yang menjadi urat nadi kehidupan masyarakat Makkah. Pembangunan sektor spritual, keagamaan, dan kebudayaan dibangun di atas prinsip bisnis, jual beli, dan untung rugi. Karena itu, saudagar kaya menjadi orang-orang yang sangat menentukan sekali dalam berbagai hal. ${ }^{19}$ Dari merekalah aturanaturan hukum dan tradisi yang berlaku dikeluarkan. Dari sinilah muncul ketidakadilan, ketimpangan, kerakusan untuk meraup untung sebanyak-banyaknya, yang pada gilirannya menjadikan kaya semakin kaya dan miskin semakin miskin.

\footnotetext{
${ }^{11}$ Badri Yatim, Sejarah Peradaban Islam Dirasah Islamiyah II (Jakarta: PT Raja Grafindo Persada, 2003 ), 15.

${ }^{12}$ Ibid.

13 Secara etimologi, muzār'ah diambil dari kata az-zar yang berarti menaburkan benih ke dalam tanah atau menanam. Baca Muhammad Ibn Abu Bakar al-Razi Mukhtār al-Șilah (Kairo: tt), 114.

14 Yakni seluruh modal datang dari pemilik, sementara pengairan, pemupukan, dan perawatannya dikerjakan oleh penggarap.

15 Yatim, Sejarah Peradaban Islam, 13.

16 Ibid., 55.

17 Ibid., 14.

${ }^{18}$ Abdur Rahman Asy Syarqowi, Muhammad Sang Pembebas: Sebuah Novel Sejarah, diterjemahkan oleh Ilyas Siraj (Yogyakarta: Mitra Pustaka, 2003), 10.

${ }^{19}$ Ibid., 11.
} 
Musim haji adalah musim perdagangan yang paling ramai. Pada saat itulah dibuka pasar-pasar Arab yang terkenal, seperti Ukaz, Dzil-Majaz, Majinnah dan lain-lainnya. ${ }^{20}$ Di antara pasar terbesar adalah pasar Ukaz. Ukaz adalah sebuah tempat perbelanjaan terlengkap yang tidak hanya dikunjungi oleh orang-orang Quraisy, tetapi juga raja-raja dan pangeran dari seluruh semenanjung Arab ikut pula menghadiri pasar Ukaz. Di Ukaz terdapat mimbar khusus sebagai tempat adu kepiawaian para penyair Arab.

Di Ukaz terdapat pula tempat penjualan budak-budak dari beraneka ragam ras, seperti budak Etiopia yang hitam, budak Rum yang putih, budak Persia, dan banyak lagi yang berasal dari India, Mesir dan Asia Tengah. ${ }^{21}$ Dengan demikian Ukaz menjadi lapangan empuk untuk mengeruk keuntungan dari kalangan rakyat jelata.

Berdasarkan kesimpulan Ahmad Amin bahwa apa yang berkembang di Makkah waktu itu merupakan pengaruh dari budaya bangsa-bangsa sekitarnya yang lebih awal maju daripada kebudayaan dan peradaban Arab. Pengaruh tersebut masuk ke jazirah Arab melalui beberapa jalur, yang terpenting di antaranya adalah (1) melalui hubungan dagang dengan bangsa lain, (2) melalui kerajaan-kerajaan protektorat di Hirah dan Ghassan, dan (3) masuknya misi Yahudi dan Kristen. ${ }^{22}$

Tentang perindustrian dan kerajinan, mereka adalah bangsa yang paling tidak mengenalnya. Kebanyakan hasil kerajinan yang ada di Arab, seperti jahit-menjahit, menyamak kulit dan lain-lainnya berasal dari rakyat Yaman, Hirah dan pinggiran Syam. Sedangkan wanita-wanita Arab cukup menangani pemintalan. Tetapi kekayaan-kekayaan yang dimiliki bisa mengundang pecahnya peperangan. Kemiskinan, kelaparan dan orangorang yang telanjang merupakan pemandangan yang biasa di tengah masyarakat. ${ }^{23}$

\section{Strategi Rasulullah Membangun Ekonomi Madinah}

Makna hijrah Rasulullah dan sahabat dari Makkah ke Madinah bukan sekadar upaya melepaskan diri dari cobaan dan cemoohan semata, tetapi di samping itu, makna hijrah juga dimaksudkan sebagai batu loncatan untuk mendirikan sebuah masyarakat baru di negeri yang aman. Itulah mengapa Rasulullah mewajibkan seluruh muslim yang di Makkah pada saat itu untuk melakukan hijrah bagi yang tak berhalangan, ${ }^{24}$ agar ikut andil dalam usaha mendirikan masyarakat baru dalam rangka menggalang kekuatan dan mengerahkan segala kemampuan untuk menjaga dan menegakkannya. ${ }^{25}$

Sebagai pemimpin, Rasulullah telah mengantongi langkah-langkah perencanaan untuk memulai intensifikasi pembangunan masyakarakat. Maka dibangunlah sebuah masjid sebagai

\footnotetext{
20 Syaikh Shafiyurrahman Al-Mubarakfury, Sirah Nabawiyah diterjamahkan oleh Kathur Suhardi (Jakarta: Pustaka al-Kausar, 1997), 62.

${ }^{21}$ Abdur Rahman Asy Syarqowi, Muhammad Sang Pembebas, 13.

${ }^{22}$ Ahmad Amin, Fajr al-Islami (Kairo: Maktabah al-Nahḍah al-Misriyah, 1975), 12.

${ }^{23}$ Syaikh Shafiyurrahman Al-Mubarakfury, Sirah Nabawiyah, 62-63.

24 Rasulullah bersabda: "Sesungguhnya telah diperlihatkan kepadaku tempat tujuan hijrah kalian, yaitu suatu tempat yang memiliki kebun kurma yang terletak di antara dua daratan subur dan memiliki batu-bau yang berwarna hitam". Setelah mendengar hadis ini, kaum Muslimin akhirnya hijrah ke Madinah. Baca lebih lanjut Imam Adz-Dzahabi, Sirah Nabi, Sejarah Kehidupan Muhammad SAW, diterjemahkan oleh Ali Murtadho, (Semarang: Pustaka Nun, 2005), 264. Tapi yang mendasar utama kenapa hijrah adalah karena adanya undangn suku Aus dan Khazraj untuk menjadi juru damai di antara mereka, karena mereka telah bosan berperang selama 40 tahun. Maka bertemulah mereka dengan Nabi di Aqabah secara bergantian.

${ }^{25}$ Syaikh Shafiyurrahman Al-Mubarakfury, Sirah Nabawiyah, 239.
} 
lokomotif pembangunan. Masjid menjadi basis etis dan moralitas dari segala aktivitas masyarakat, sekaligus sumber pergerakan kaum muslimin untuk merumuskan segala kebijakan-kebijakan demi untuk menegakkan prinsip sosial dan nilai-nilai kemanusiaan. Hal ini juga dapat dimaknai bahwa masjid menjadi wadah perekat antara aktivitas ukhrāwi dan duniawi, dengan kata lain tidak ada dikotomi antara dimensi akhirat dan dimensi dunia. Karena ilmu akhirat yang memiliki orientasi vertikal menjadi sumber etis dan koridor paradigma di dalam mengembangkan dinamika ilmu mu'amalah yang orientasinya horizontal.

Dengan demikian, eksistensi substansi masjid bukanlah sesuatu yang didasarkan kepada idealisme semata, yang hanya difungsikan sebagai tempat beribadah dalam arti sempit saja, tetapi memiliki sederet fungsi untuk memfasilitasi kebutuhan masyarakat, baik kebutuhan yang bersifat spritual maupun yang bersifat material. Di antara fungsi masjid adalah sebagai tempat jual beli, ${ }^{26}$ karena ini merupakan tuntutan realitas keadaan masyarakat waktu itu yang memerlukan struktur perkonomian yang baru, karena struktur perekonomian yang ada dikuasai dan dimonopoli sepenuhnya oleh orang-orang Yahudi dan diatur sepenuhnya oleh sistem kapitalis Yahudi.

Namun dalam perkembangan selanjutnya, dipindahkanlah aktivitas jual beli dari lingkungan masjid demi menjaga kekhusyuan ibadah mahdah. ${ }^{27}$ Aktivitas jual beli ini difokuskan di pasar yang diberi nama "Suqul Anshar" atau pasar Anshar. Pasar ini dibangun oleh Abdurrahman bin Auf, seorang hartawan yang kaya raya atas arahan Rasulullah. Pasar ini dikelola seratus persen oleh umat Islam sendiri berlokasi tidak jauh dari pasar Yahudi. Semua orang Islam dihimbau untuk berjual beli dan melakukan semua aktivitas perdagangan di pasar itu tanpa bekerjasama sedikitpun dengan Yahudi dan tanpa terlibat dengan segala produk atau barang mereka. ${ }^{28}$

Pasar Islami yang dibangun Rasulullah, keistimewaannya bukan pada infrastruktur pasar dan sistem transaksinya, tetapi lebih kepada values yang ditanam Rasulullah sebagai fondasi etis prilaku pasar (market conduct), agar terbangun pasar yang menjunjung tinggi kejujuran dan keadilan. Terdapat aturan-aturan yang tidak boleh dilanggar, termasuk di dalamnya praktek transaksi yang tidak sesuai dengan nilai-nilai Islam. Kebijakan ini sematamata dalam rangka menjaga stabilitas harga dan keseimbangan perekonomian dan tetap berjalan sesuai dengan nature-nya. Karena pada prinsipnya, aktivitas ekonomi adalah aktivitas alamiah, tarik-menarik antara faktor demand dan supply yang tentu saja bersih dari praktek manipulasi, distorsi dan ketidakjujuran. Selain itu, Rasulullah pun telah menerapkan pola bisnis dengan persaingan yang sehat, tanpa menggunakan wewenang kekuasaannya untuk menutup pasar Yahudi, mengingat kedudukan Rasulullah pada saat itu adalah seorang pemimpin, tetapi justru Rasulullah sepenuhnya menyerahkan penilaiannya kepada masyarakat. Dan pada akhirnya ekonomi Yahudi yang sudah ratusan tahun, gulung tikar dan bangkrut bahkan mereka menjadi miskin dan akhirnya menutup pasar mereka.

Inilah fakta ketika etika autentik diterapkan secara utuh, maka segala bentuk kerusakan di dalam ekonomi, seperti ketidakjujuran, anomali dan distorsi yang tengah terjadi di dalam

\footnotetext{
${ }^{26}$ M. Abdul Karim. Sejarah Kebudayaan Islam, 68.

${ }^{27}$ Ibid.

${ }^{28}$ Firman, "Kisah Rasulullah Membangun Sistem Ekonomi Islam”, dikutip dari http:/ /kawansejati.ee.itb. ac.id/ diakses tanggal 7 Desember 2017.
} 
pasar bisa terurai dengan sendirinya tanpa harus mengeluarkan kebijakan-kebijakan yang berpihak, miring dan tidak seimbang, sehingga pada akhirnya justru akan menambah persoalan baru. Perbaikan sistem ekonomi tanpa diiringi dengan paradigma etis dan keteguhan akhlak dapat digambarkan seperti peribahasa "seperti ingin menegakkan benang yang lagi basah".

Selain itu, ukhuwwah islämiyah atau persaudaraan sesama muslim, antara golongan Muhājirīn dan golongan Anshār sangat ditekankan oleh Rasulullah. Rasulullah sangat menyadari bahwa kebersamaan, kekeluargaan dan persaudaraan merupakan salah satu prasyarat dalam kehidupan berbangsa dan bernegara. Bukan hanya berfaedah bagi kekuatan secara politik saja, tetapi juga dapat mendongkrak pertumbuhan ekonomi masyarakat. Paradigma ekonomi yang dibangun oleh Rasulullah adalah paradigma komunal-sosial, bukan pandangan yang terbatas pada kerangka individual. Pandangan Islam terhadap ekonomi adalah bagian yang tidak terlepaskan dari aktivitas sosial, sehingga masyarakat sosial yang melakukan aktivitas ekonomi harus dibantu dan diberdayakan secara adil dan berkelanjutan (sustainable) oleh negara agar aktivitas ekonomi dapat berjalan secara seimbang dan proporsional.

Dari sini terlihat bahwa pemikiran ekonomi Rasulullah orientasi substanstifnya adalah "kepada kepentingan bersama masyarakatlah yang diutamakan". Bahkan untuk tercapainya arah dan tujuan dimaksud, Rasulullah sangat menekankan terciptanya "efesiensi social". Artinya bagaimana ekonomi negara bisa dikelola secara bersama dengan baik dan ketepatgunaan yang tinggi sehingga kemakmuran dan kesejahteraan dalam arti yang sesungguhnya.

Oleh karena itu, prinsip sebesar-besar kemakmuran rakyat dalam pandangan ekonomi Rasulullah adalah sangat dikedepankan. Implikasi dari pandangan ini adalah perintah Rasullah untuk saling tolong-menolong antar sesama dalam segala aktivitas kehidupan, terutama dalam tatanan ekonomi. Hak warisan harta ditinggalkan atas dasar saudara seagama, tanah kepunyaan Anshār digarap bersama-sama dengan Muhājirīn. ${ }^{29}$

Sehingga pada saat itu, dengan sistem al-muzära'ah, al-mu'ājarah yang diterapkan di atas prinsip al-ta'âwun. ${ }^{30}$ Capaian dari sistem ini adalah Madinah menjadi kaya dengan produksi dari hasil tanaman gandum, sayur-sayuran, buah-buahan dan juga barli. Tidak hanya itu, kota ini juga adalah pengeluar terbesar buah kurma atau tamr terutama menjelang musim kemarau. ${ }^{31}$ Dari penghasilan ini saja, kota Madinah dapat memainkan peranan penting dalam perekonomian di kawasan sekitarnya. ${ }^{32}$

\footnotetext{
${ }^{29}$ M. Abdul Karim. Sejarah Kebudayaan Islam, 69.

${ }^{30}$ Sebelum Islam hadir, di Madinah masih berlaku sistem muzābanah, muhālaqah, mukhābarah, mu'āwamah. Dan ketika Islam datang, Nabi melarangnya, karena mengandung gharăr (spkulasi). Muzābanah, yakni membeli buah kurma basah dengan kurma kering yang masih di atas pohon. Muhăqalah adalah menyewakan kebun dengan pembayaran makanan (bahan makanan) dalam takaran yang ditentukan. Mukhäbarah adalah menyewakan kebun atau ladang dengan pembayaran $1 / 3$ atau $1 / 4$ hasil panennya. Muāwammahadalah menyewakan kebun buah selama beberapa tahun untuk dipungut buahnya.

31 Ahli Fiqir Ehoza, "Cara Rasulullah Atasi Krisis Ekonomi", dikutip dari http://www.ehoza.com/ diakses tanggal 7 Desember 2017.

${ }^{32}$ Situasi Madinah dapat dilihat dari gambaran yang diinformasikan al-Quran yang maksud-Nya: Dan di bumi terdapat bahagian-bahagian yang berdampingan, dan kebun-kebun anggur, tanam-tanaman dan pohon kurma yang bercabang, disirami dengan air yang sama. Kami melebihkan sebahagian tanam-tanaman itu atas sebahagian yang lain tentang rasanya. Sesungguhnya yang demikian itu terdapat tanda-tanda bagi kaum yang berfikir. (al-Ra'du: 4).
} 
Inilah makna efisiensi sosial atau "efisiensi berkadilan", karena memang dalam pandangan Rasulullah manusia sebagai makhluk individu sekaligus makhluk sosial, sehingga keadilan dan pemerataan distribusi pendapatan yang harus diutamakan, bukanlah dititikberatkan pada hasil pembangunan dan capaian pertumbuhan ekonomi yang spektakuler. Pandangan ini sudah barang tentu berangkat dari nilai-nilai Qurani yang menghormati sesama manusia dan menekankan masalah ukhuwah/ persaudaraan (Qs. al-Hujurāt: 10), ta'āwun/ tolong menolong/ kebersamaan (Qs. al-Maidah: 3).

Di samping itu, kebijaksanaan Rasulullah dalam bidang ekonomi juga terlihat ketika Rasulullah tidak serta merta membebankan, uss $r^{33}$ dan jizyah bagi non-muslim pada saat pondasi masyarakat belum begitu kokoh. Tapi ketika masyarakat Madinah memiliki pondasi yang kuat dan menampakkan embrio kekuatan, baik di bidang politik maupun ekonomi, barulah Rasulullah merancang sistem pemerintahan yang ditandai dengan disepakatinya "Piagam Madinah". ${ }^{44}$ Terlihat salah satu nilai etis yang menonjol pada kebijkan adalah fleksibilitas dan proporsinalitas. Kebijakan yang tidak mengikat, tetapi kebijkan yang solutif berdasarkan situasi dan keadaan.

Dengan disepakatinya Piagam Madinah, Islam semakin kuat dan perkembangannya yang pesat membuat orang-orang Makkah merasa risau. Kerisauan ini akan mendorong orang Quraisy bertindak apa saja. Di satu sisi, Madinah hampir tidak memiliki pemasukan atau pendapatan negara. ${ }^{35}$ Untuk menghadapi kemungkinan itu, maka Rasulullah menggalang kekuatan berupa pembentukan militer dan juga menganjurkan kontribusi finansial yang sifatnya sukarela dalam rangka membantu mempertahankan diri dari serangan musuh, dalam beberapa literatur, kebijakan ini disebut takäful. Dalam konteks ini, kebijakan takäful tidak hanya menggambarkan keadaan darurat negara, tetapi values yang disampaikan Rasulullah adalah bahwa negara bukan milik segilintir elit penguasa, tetapi hakikatnya negara adalah milik rakyat, dari rakyat untuk rakyat.

Pada tahun ketujuh Hijriyah, kaum muslimin berhasil menaklukan Khaibar. Tanah hasil taklukan dikelola dengan menerapkan sistem kharāj, yakni pajak tanah yang dipungut dari non-muslim. Dan sistem ini diterapkan di berbagai daerah taklukan, dan dalam perkembangannya, kharāj menjadi salah satu sumber pendapatan negara terpenting. ${ }^{36}$ Dalam masa pemerintahannya juga, Rasulullah menerapkan jizyah, yakni pajak yang dibebankan kepada orang-orang non-muslim, khususnya ahli kitab, sebagai perlindungan jiwa, harta milik, kebebesan menjalankan ibadah, serta pengecualian dari wajib militer. ${ }^{37}$ Pajak jizyah bagi non-muslim, bukan bagian dari ketidakadilan, tetapi justru untuk menegakkan keadilan. Pada saat, itu masyarakat non-muslim tidak diwajibkan membayar zakat sekaligus tidak ada

\footnotetext{
33 Yang dimaksud dengan uṣr dalam konteks ini adalah zakat atas hasil pertanian dan buah-buahan, bukan uss dalam bea impor.

${ }^{34}$ Sebuah piagam yang menjamin kebebasan beragama orang-orang Yahudi sebagai suatu komunitas. Setiap golongan masyarakat memiliki hak tertentu dalam bidang politik dan keagamaan. Kemerdekaan beragama dijamin dan seluruh anggota bermasyarakat berkewajiban mempetahankan keamanan negeri itu dari serangan luar. Baca lebih lanjut Harun Nasution, Islam Ditinjau dari Berbagai Aspek, jilid 1 (Jakarta: UI Press, 1985), 101.

35 Adiwarman Azwar Karim, Sejarah Pemikiran Ekonomi Islam, edisi ketiga (Jakarta: PT Raja Grafindo Persada, 2004), 37.

36 Ibin., 44.

37 Ibid., 43.
} 
kewajiban militer. Maka atas dasar persamaan hak dan kewajiban di bawah negara, maka pajak jizyah bagi non-muslim menjadi sesuatu yang wajib.

\section{Kesimpulan}

Dari penjelasan di atas, dapat diketahui bahwa aktitivitas ekonomi bangsa Arab praIslam telah menjadi pusat dunia atau sebagai World Trade Center, baik di bagian selatan jazirah Arab (Yaman) yang dikelola oleh kerajaan Saba' dan pemerintah Himyar dengan sektor pertanian yang dominan karena memiliki tanah yang subur dan didukung dengan adanya bendungan raksasa Maarib, maupun di bagian utara Arab, Hijaz (Makkah) yang dipengaruhi oleh pihak luar seperti Persia dan Romawi, dengan sektor perdagangan yang terunggul, karena memang wilayahnya tandus dan gersang, tapi letak geografisnya stratgis sebagai tempat persinggahan para kafilah.

Adapun karakteristik perekonomian masa Rasulullah adalah sosialis-religius yang menekankan partisipasi kerja kooperatif yang diberlakukan bagi kaum Muhājirīn dan Anshār yang menyebabkan meningkatnya distribusi pendapatan dan kesejahteraan. Dari sinilah terlihat konsep demokrasi ekonomi Rasulullah yang tidak harus diartikan sebagai berlakunya prinsip equal treatment (perlakuan sama), karena menurut Rasulullah orang yang tidak berpunya perlu memperoleh pemihakan dan bantuan yang berbeda (partial treatment). Pada prinsipnya Rasulullah sangat mengutamakan tercapainya kesejahteraan bersama.

\section{Daftar Rujukan}

Amin, Ahmad. Fajr al-Islāmi. Kairo: Maktabah al-Nahḍah al-Mișriyah, 1975.

Davies, Roy and Glyn Davies. The History of Money from Ancient Time of Present Day. New York: Oxport University Press, 1996.

Ehoza, Ahli Fiqir. "Cara Rasulullah Atasi Krisis Ekonomi” dikutip dari http://www. ehoza. $\mathrm{com} / \mathrm{v} 4 /$ forum/info- pengetahuan-am/51857-cara-rasulullah-atasi-krisis-ekonomi.html, akses tanggal 7 Desember 2017.

Firman. "Kisah Rasulullah Membangun Sistem Ekonomi Islam" dikutip dari http:/ /kawansejati.ee.itb. ac.id/ kisah- rasulullah-membangun-sistem-ekonomi-islam, diakses tanggal 7 Desember 2017

Karim, Adiwarman Azwar. Sejarah Pemikiran Ekonomi Islam, edisi ketiga. Jakarta: PT Raja Grafindo Persada, 2004.

Karim, M. Abdul. Sejarah Pemikiran dan Peradaban Islam. Yogyakarta: Pustaka Book Publisher, 2007.

Khan, Muhammad Akram. An Intrduction to Islamic Economics. Islamabad: IIIT Pakistan, 1989.

Kholis, Nur. "Penegakan Syariat Islam di Indonesia: Perspektif Ekonomi”. Jurnal Ilmiah Al Mawarid FIAI UII. Edisi XVI Tahun 2006.

Leboun, Gustav. Haḍarāt al-Arab. Kairo: Maṭba'ah İsā al-Bābi al-Ḥalabi, t.th.

Mubarakfury, Syaikh Shafiyurrahman. Sirah Nabawiyah. Jakarta: Pustaka al-Kausar, 1997.

Nasution, Harun. Islam Ditinjau dari Berbagai Aspek, jilid 1. Jakarta: UI Press, 1985.

Swasono, Sri Edi. Ekspose Ekonomika Globalisme dan Kompetensi Sarjana Ekonomi. Yogyakarta: Pusat Studi Ekonomi Pancasila (Pustep)-UGM, 2003. 
Syarqowi, Abdur Rahman. Muhammad Sang Pembebas: Sebuah Novel Sejarah. Yogyakarta: Mitra Pustaka, 2003.

Yatim, Badri. Sejarah Peradaban Islam Dirasah Islamiyah II. Jakarta: PT Raja Grafindo Persada, 2003. 